\title{
Total arterial coronary grafting: outcomes, concerns and controversies
}

\author{
Shahzad G. Raja \\ Department of Cardiac Surgery, Harefield Hospital, Hill End Road, Harefield, Middlesex UB9 6JH, UK.
}

Correspondence to: Dr. Shahzad G. Raja, Department of Cardiac Surgery, Harefield Hospital, Hill End Road, Harefield, Middlesex UB9 6JH, UK. E-mail: drrajashahzad@hotmail.com

How to cite this article: Raja SG. Total arterial coronary grafting: outcomes, concerns and controversies. Vessel P/us 2019;3:23. http://dx.doi.org/10.20517/2574-1209.2019.05

Received: 27 Mar 2019 First Decision: 22 Apr 2019 Revised: 11 Jun 2019 Accepted: 12 Jun 2019 Published: 11 Jul 2019

Science Editor: Mario F. L. Gaudino Copy Editor: Cai-Hong Wang Production Editor: Jing Yu

\begin{abstract}
Choice of conduit remains the Achilles heel of coronary artery bypass grafting. Conduit choice is crucial as it is deemed to influence the long-term outcomes. While the important survival advantage of a left internal mammary artery graft over vein grafts is universally accepted, controversy reigns supreme regarding the next best conduit. There is plenty of evidence to suggest that arterial grafts are not only superior in terms of patency and survival, but they also protect the native coronary arteries against further progression of atherosclerotic disease. Total arterial coronary grafting, utilizing various configurations of bilateral internal mammary arteries, radial artery and occasionally right gastroepiploic artery is a safe and reproducible strategy. However, concerns about additional operative time, enhanced technical complexity, graft spasm with hypoperfusion, competitive flow, increased risk of bleeding, deep sternal wound infection, and most importantly lack of randomized trial data have prevented the universal adoption of total arterial coronary grafting. This review evaluates the currents outcomes of total arterial coronary grafting and summarizes the concerns and controversies associated with this strategy.
\end{abstract}

Keywords: Coronary artery bypass grafting, bilateral internal mammary artery grafting, multiple arterial grafting, total arterial grafting, total arterial revascularization

\section{INTRODUCTION}

Coronary artery bypass grafting (CABG) remains, more than five decades after its introduction into clinical practice, the most scrutinized surgical procedure and a therapeutic intervention of paramount 
importance for patients with coronary artery disease ${ }^{[1]}$. The choice of the graft conduit for CABG has significant impact both on the short- and long-term outcomes. The patency of a coronary conduit is fundamentally related with a smooth postoperative course, improved long-term patient survival and enhanced freedom from re-intervention ${ }^{[2]}$. Long saphenous vein has been the most commonly used conduit in CABG. However, progressive saphenous vein graft (SVG) failure remains a major impediment to the long-term success of $\mathrm{CABG}^{[3]}$. Total arterial coronary grafting also known as total arterial revascularization (TAR) is a logical solution to deal with late vein graft atherosclerosis, and occlusion.

\section{RATIONALE}

Arterial coronary grafts are relatively resistant to atheromatous changes and have better patency rates, resulting in less recurrent angina, fewer myocardial infarctions and reoperations and better survival than with SVGs ${ }^{[4]}$. Hence it is logical to use arterial grafts instead of SVGs. Multiple large studies have documented better long-term outcomes for CABG with two internal mammary arteries (IMAs) over one $\mathrm{e}^{[5-7]}$. Arterial grafts (unlike SVGs) also synthesize and release nitric oxide and other favorable vasoactive agents that protect the coronary artery downstream from development of further atheromatous changes ${ }^{[8]}$.

\section{CURRENT UTILIZATION RATES}

Utilization rates of TAR are variable. It is estimated that about 20\% CABG procedures in Europe utilize TAR while utilization rates are up to $80 \%$ at some centers in Australia. On the other hand, in North America almost $5 \%$ of patients undergoing CABG receive $\mathrm{TAR}^{[9-11]}$. This large variation in practice can be partially attributed to the paucity of evidence from adequately powered randomized controlled trials (RCTs) with long-term follow-up. Furthermore, increasingly complex patient profiles and enhanced scrutiny facing the cardiac surgeons in an era of public reporting of surgeon-specific mortality data may also impact adoption rates of TAR.

\section{CONFIGURATIONS}

The deployment of arterial grafts and their configuration is generally dictated by the availability of conduits, the degree of stenosis in the native coronary arteries and the technical expertise of the surgeon. There are numerous potential configurations that can be achieved during TAR highlighting the fact that that there is no single operation that is suitable for every patient - it is not a case of "one size fits all" as would be the scenario for the use of a single internal mammary artery and supplemental vein grafts ${ }^{[12]}$.

\section{Bilateral internal mammary arteries}

Several configurations have been used to accomplish TAR of left-sided coronary system with bilateral internal mammary arteries (BIMA) only ${ }^{[13]}$. These include in situ right internal mammary artery (RIMA) to the left anterior descending (LAD) artery and the left internal mammary artery (LIMA) to circumflex marginal branches ${ }^{[14]}$ [Figure 1], routing the RIMA through the transverse sinus in a retroaortic course ${ }^{[15]}$ [Figure 2], and free RIMA grafts anastomosed proximally either to the $\operatorname{LIMA}^{[16]}$ [Figure 3] or to the ascending aorta ${ }^{[17]}$. Table 1 summarizes the pros and cons of these configurations.

\section{Radial artery}

The radial artery can be combined with BIMA to achieve TAR. The radial artery from the aorta to the posterior descending artery (PDA) is an attractive approach in the presence of $80 \%$ or more stenosis in the right coronary artery (RCA) or ideally if the RCA is completely blocked thereby reducing competitive flow [Figure 4]. An alternative strategy, especially if a no touch aortic technique is indicated, is to use the main body of the RIMA to construct a composite left-sided graft while anastomosing the radial artery to the proximal in situ RIMA $^{[12]}$. The RIMA will frequently fail to reach the PDA even after full 


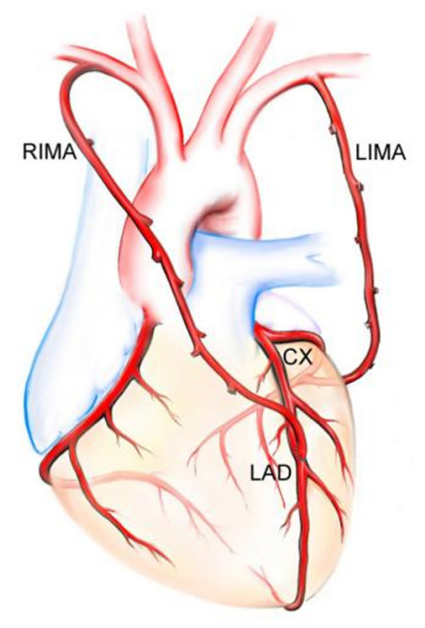

Figure 1. In situ right internal mammary artery (RIMA) to the left anterior descending (LAD) artery and the left internal mammary artery (LIMA) to circumflex (Cx) marginal branches. (Figure courtesy Marcie Bunalade)

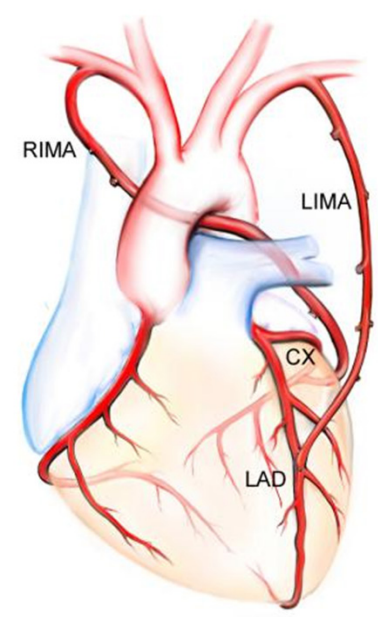

Figure 2. In situ left internal mammary artery (LIMA) to the left anterior descending (LAD) artery and the in situ right internal mammary artery (RIMA) through the transverse sinus in a retroaortic course to the circumflex $(C x)$ marginal branches. (Figure courtesy Marcie Bunalade)

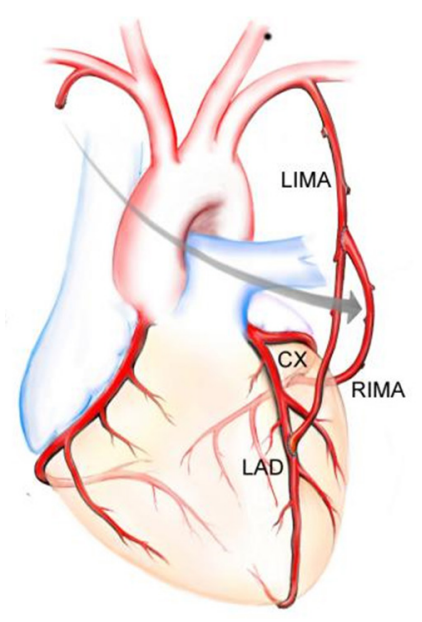

Figure 3. Composite $Y$ graft with free right internal mammary artery (RIMA) connected proximally to the left internal mammary artery (LIMA) with LIMA anastomosed to the left anterior descending (LAD) artery and RIMA anastomosed to the circumflex (CX) marginal branches. (Figure courtesy Marcie Bunalade) 


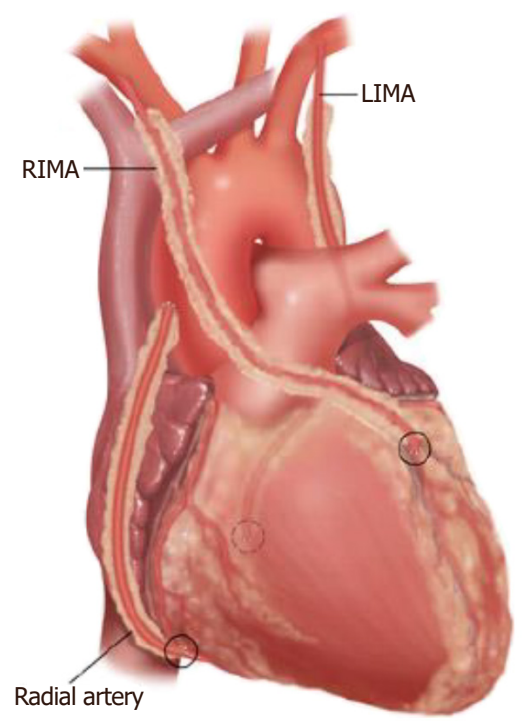

Figure 4. Radial artery from the aorta to the posterior descending artery with in situ right internal mammary artery (RIMA) anastomosed to the left anterior descending artery and in situ left internal mammary artery (LIMA) anastomosed to the circumflex marginal branches. (Figure courtesy Marcie Bunalade)

Table 1. Configurations of bilateral internal mammary arteries

\begin{tabular}{|c|c|c|}
\hline Configuration & Pros & Cons \\
\hline $\begin{array}{l}\text { Retroaortic in situ RIMA via } \\
\text { transverse sinus to circumflex } \\
\text { marginal branches with in situ } \\
\text { LIMA to LAD }\end{array}$ & $\begin{array}{l}\text { The LAD is revascularized by the in situ LIMA, which is } \\
\text { well accepted as a gold standard technique } \\
\text { The left coronary system is perfused by } 2 \text { in situ IMAs } \\
\text { It avoids the difficulties of anastomosing a thin-walled } \\
\text { vessel, such as the free RIMA, to a thick-walled vessel, } \\
\text { such as the aorta } \\
\text { There are no grafts crossing the midline behind the } \\
\text { sternum, and both IMAs are in a safe position, which } \\
\text { decreases the risks in case of mediastinal revision or } \\
\text { reoperation } \\
\text { It offers the possibility to easily apply the no-touch } \\
\text { principle by using different composite graft configurations. }\end{array}$ & $\begin{array}{l}\text { The inability to control bleeding from } \\
\text { retroaortic RIMA branches } \\
\text { Aortic compression of the in situ } \\
\text { RIMA, and compromised graft patency } \\
\text { because of undetected kinks, graft } \\
\text { overstretching, rotation, and spasm of } \\
\text { distal RIMA }\end{array}$ \\
\hline $\begin{array}{l}\text { Retrosternal crossover in situ } \\
\text { RIMA to LAD with in situ LIMA to } \\
\text { circumflex marginal branches }\end{array}$ & $\begin{array}{l}\text { This strategy is easily reproducible and technically less } \\
\text { demanding } \\
\text { The LAD is grafted by an intact in situ IMA, complete left- } \\
\text { sided IMA grafting is readily achieved, and the principle } \\
\text { of multiple-origin blood supply is maintained } \\
\text { The additional length obtained by harvesting the IMA as } \\
\text { a skeletonised vessel enables better selection of the LAD } \\
\text { anastomotic site and precludes the use of the more distal } \\
\text { vasospastic RIMA segments }\end{array}$ & $\begin{array}{l}\text { The potential risk of damage to the } \\
\text { artery during repeat sternotomy }\end{array}$ \\
\hline $\begin{array}{l}\text { Composite LIMA-RIMA T or Y } \\
\text { grafting }\end{array}$ & $\begin{array}{l}\text { The composite anastomosis is ideally matched and avoids } \\
\text { the problems of proximal anastomoses to the aorta } \\
\text { The aortic "no touch" technique reduces the risk of stroke } \\
\text { and is particularly useful in off pump surgery } \\
\text { A greater length of RIMA is available for more extensive } \\
\text { myocardial revascularization, perhaps avoiding the use of } \\
\text { a third conduit }\end{array}$ & $\begin{array}{l}\text { Single source blood supply with steal } \\
\text { phenomenon, competitive flow, and } \\
\text { hypoperfusion syndrome as potential } \\
\text { disadvantages }\end{array}$ \\
\hline $\begin{array}{l}\text { Right internal mammary artery for } \\
\text { grafting the right coronary system }\end{array}$ & $\begin{array}{l}\text { The aortic "no touch" technique reduces the risk of stroke } \\
\text { and is particularly useful in off pump surgery }\end{array}$ & $\begin{array}{l}\text { Gross mismatch between RCA and } \\
\text { RIMA sizes } \\
\text { Usage of the distal part of the pedicled } \\
\text { RIMA to graft PDA increases the risk } \\
\text { of vasospasm }\end{array}$ \\
\hline
\end{tabular}

LIMA: left internal mammary artery; PDA: posterior descending artery; RCA: right coronary artery; RIMA: right internal mammary artery 
A

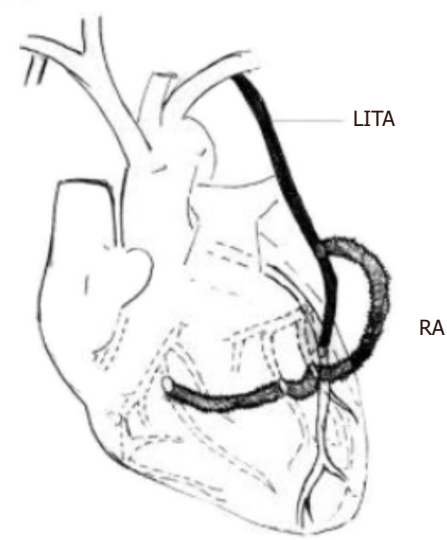

B

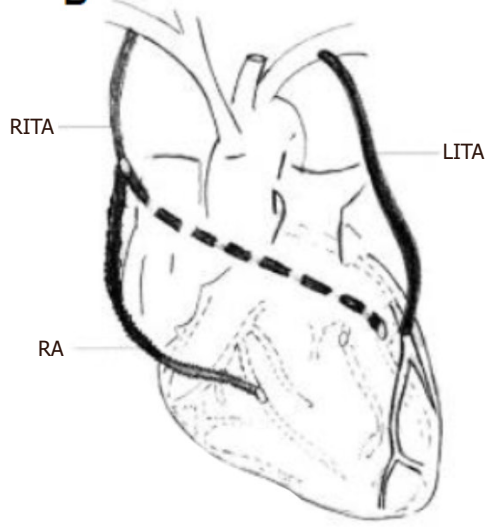

C

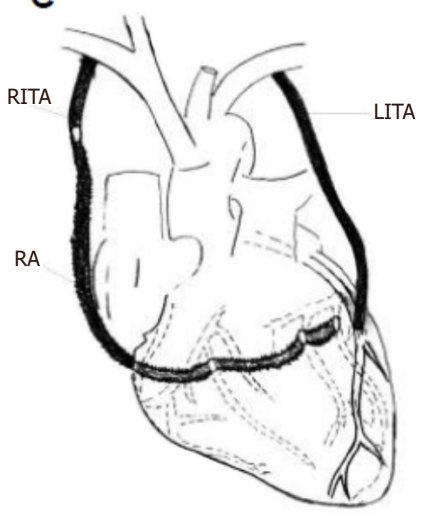

Figure 5. Composite configurations of radial artery. A: Radial artery (RA) Y or T graft from the in situ left internal mammary artery (LITA) anastomosed to the circumflex marginal branches and distal branches of right coronary artery; B: RA Y or T graft from the in situ right internal thoracic artery (RITA) anastomosed to the distal branches of right coronary artery; C: Extension of RITA with RA. (Figure courtesy Marcie Bunalade)

skeletonization and can be lengthened with recycled LIMA or radial artery [Figure 5]. The RIMA should not be anastomosed to the main RCA because of the possibility of competitive flow due to size disparity and ultimately evolution of progressive disease at the crux ${ }^{[12]}$.

\section{Right gastroepiploic artery}

The right gastroepiploic artery can be combined with in situ RIMA to the LAD and LIMA to the obtuse marginal. Right gastroepiploic artery is particularly useful for grafting an occluded dominant ungrafted RCA or one with a failed graft in the presence of patent grafts to the left side. Grafting of the PDA can be achieved off-pump through a reasonably small incision via the lower sternum.

\section{OUTCOMES}

\section{Perioperative outcomes}

The perioperative outcomes of TAR are similar to those of conventional CABG. Majority of the studies report $1 \%$ mortality and a $1 \%-3 \%$ rate for stroke, intra-aortic balloon pump use and myocardial infarction ${ }^{[18-21]}$. There is increasing acceptance that TAR should be offered only to younger patients (usually now perceived as less than 70 years old), predominantly with preserved ventricular function and absence of significant co-morbidity, as they are more likely to benefit from the superior long-term patency of the arterial grafts ${ }^{[12]}$. However, TAR in combination with off-pump CABG can also be offered to the elderly to allow a true "no touch aortic technique" where there is robust evidence for a reduction in the risk of most major complications and, in particular, stroke ${ }^{[2]}$. There is evidence from RCTs that TAR with composite grafts is a safe and useful procedure in the elderly ${ }^{[23-25]}$.

\section{Long-term outcomes}

The added value of TAR in CABG becomes particularly apparent when assessing long-term results. Tavilla et al. ${ }^{[26]}$ recently reported 20 -year outcomes of TAR using BIMA and gastroepiploic artery as in situ grafts in patients with 3-vessel disease. The Kaplan-Meier estimated survival probabilities were 73.9\% (95\%CI: 67.2\%-79.5\%) and 63.5\% (95\%CI: 55.7\%-70.4\%) for overall survival and 57.9\% (95\%CI: 50.7\%$64.5 \%$ ) and $47.9 \%$ (95\%CI: $40.1 \%-55.3 \%$ ) for freedom from major adverse cardiac events at 15 and 20 years respectively. The respective estimated cumulative incidences at 15 and 20 years were $7.0 \%$ (95\%CI: 3.5\%$10.6 \%$ ) and $7.8 \%$ 95\%CI: $4.0 \%-11.6 \%$ ) for myocardial infarction, 8.6\% (95\%CI: 4.7\%-12.5\%) and 9.3\% (95\%CI: 5.2\%-13.3\%) for percutaneous reintervention, $7.0 \%$ (95\%CI: 3.5\%-10.5\%) and 7.0\% (95\%CI: $3.5 \%-10.5 \%$ ) for 
reoperation, $8.6 \%$ (95\% CI, 4.7\%-12.6\%) and $12.9 \%$ (95\% CI, 7.6\%-18.2\%) for cardiac death, and $10.8 \%$ (95\% CI, 6.5\%-15.2\%) and $15.2 \%$ (95\% CI, 9.8\%-20.6\%) for death from other causes.

Tatoulis and colleagues ${ }^{[27]}$ in a mulitcentre analysis compared outcomes in patients who underwent TAR $(n=12,271)$ with outcomes in those who did not $(n=21,910)$. They determined the impact of TAR on 10-year all-cause late mortality by propensity score analyses in 6,232 matched pairs. The 30 -day mortality was $0.8 \%$ $(96 / 12,271)$ for TAR patients and $1.8 \%(398 / 21,910)$ for non-TAR patients $(P<0.001)$. Late mortality was $7.5 \%$ $(918 / 12,271)$ for TAR patients and $8.9 \%(1,952 / 21,910)$ for non-TAR patients $(P<0.001)$. The mean follow-up time was 4.9 years. In the propensity-matched cohort, the perioperative mortality was $0.9 \%(53 / 6,232)$ for TAR patients versus $1.2 \%(76 / 6,232)$ for non-TAR patients $(P<0.001)$. Kaplan-Meier survival in the matched cohort at 1,5 , and 10 years was $97.2 \%, 91.3 \%$, and $85.4 \%$ for TAR patients and $96.5 \%, 90.1 \%$, and $81.2 \%$ for non-TAR patients $(P<0.001)$. Late mortality was $8.0 \%(n=500)$ for TAR patients and $10.0 \%(n=622)$ for non-TAR patients $(P<0.001)$. Stratified Cox proportional hazards models showed lower risk for all-cause late mortality in the TAR group (TAR:HR $0.80,95 \%$ confidence interval 0.71 to $0.90, P<0.001$ ).

A systematic review and meta-analysis of 130,305 patients from 4 smaller shorter follow-up RCTs, plus 15 matched/adjusted and 6 unmatched/unadjusted larger longer follow-up observational studies suggested that TAR may improve long-term survival compared with conventional CABG by $15 \%-20 \%$ even when compared with two arterial grafts ${ }^{[28]}$.

\section{CONCERNS}

\section{Single blood source}

The composite grafting technique has the disadvantage of complete reliance of the coronary bypass flow on the flow of the proximal IMA. Multiple clinical and experimental studies have assessed the adequacy of the IMA as the sole blood source in composite arterial grafting ${ }^{[29,30]}$. Sakaguchi and colleagues ${ }^{[30]}$, utilizing positron emission tomography, demonstrated that the composite Y graft was not as efficient as independent grafts for increasing the coronary flow reserve soon after bypass grafting. However, most investigations have reported that the flow reserve of the proximal IMA is adequate as a blood source of composite grafts in TAR. Affleck et al ${ }^{[31]}$, in an effort to determine the constraint posed by a single source inflow recorded intraoperative flow in each limb of the T graft before and after distal anastomoses in 204 patients. They also compared flow capacity with completion coronary flow. Free flow for the radial arterial limb was reported as $161 \pm 81 \mathrm{~mL} / \mathrm{min}$, the IMA limb as $137 \pm 57 \mathrm{~mL} / \mathrm{min}$ (combined $298 \pm 101 \mathrm{~mL} / \mathrm{min}$ ) compared with simultaneous limb flow of $226 \pm 84 \mathrm{~mL} / \mathrm{min}$ resulting in a flow restriction of $24 \% \pm 14 \%$. Completion coronary flow was $88 \pm 49 \mathrm{~mL} / \mathrm{min}$ for the radial artery, $60 \pm 45 \mathrm{~mL} / \mathrm{min}$ for the IMA, and $140 \pm 70 \mathrm{~mL} / \mathrm{min}$ for both limbs simultaneously to give a flow reserve ( $v$ s. simultaneous free flow) of $160 \%$ or 1.6. This flow reserve of 1.6 compares favorably with an IMA flow reserve of 1.8 at 1-month postoperatively and 1.8 for both the IMA T graft and the IMA/radial artery T graft at 1-week postoperatively as reported by Wendler and associates ${ }^{[32]}$.

\section{Graft spasm and hypoperfusion}

Hypoperfusion syndrome, associated with a high mortality, is a recognized sequela of vasospasm of arterial grafts. Spasm of the proximal IMA in case of composite grafting may result in hypoperfusion of the whole left coronary system and may lead to calamitous consequences ${ }^{[30]}$. Similarly, the radial artery and gastroepiploic artery with an enhanced spasmodic tendency, owing to preponderance of smooth muscle, predispose to a risk of hypoperfusion due to spasm of these vessels if used to construct a composite graft ${ }^{[33]}$.

In practice however, $1 \%$ to $2 \%$ of the patients undergoing composite arterial grafting experience perioperative hypoperfusion resulting in myocardial ischemia, infarction, low output states, or even extreme hypotension ${ }^{[33,34]}$. Injury to the conduit during harvest, technical errors in the anastomosis, linear 
tension on the conduit, angulation at anastomotic site, and unresolved harvest spasm are recognized reasons for hypoperfusion syndrome ${ }^{[3,34]}$. Preoperative angiographic evaluation of the quality of the IMA conduit and the subclavian artery, careful conduit harvesting and meticulous construction of anastomoses, insertion of $1.5-\mathrm{mm}$ flexible probe into the IMA and the radial artery after harvesting, and flow measurement using transit time Doppler flow meter after completion of anastomosis are some of the strategies which can mitigate the risk of perioperative hypoperfusion ${ }^{[33,35]}$.

\section{Competitive flow}

Another concern is the augmented risk of competitive flow in the composite graft in comparison with the individual bypass graft. Competitive flow reduces the antegrade flow especially in the diastole, and the phasic delay in pressure wave in the IMA causes a retrograde flow in the early systole ${ }^{[33]}$. This oscillating flow pattern in the competitive scenario influences the endothelium. The release of nitric oxide and prostacyclins is affected leading to string sign, which is considered a physiologic vasoconstriction of the arterial graft. String sign is associated with moderate stenosis in the target coronary artery ${ }^{[29,35]}$ and results in failure of the arterial graft ${ }^{[35,36]}$.

In the composite graft, the mechanism of competitive flow is more intricate than that in the individual graft. In addition to the relation between the graft and its target coronary branch where competitive flow occurs, the interactions of all anastomosed branches within the composite graft, the phasic delay between the in situ grafts, and the whole graft arrangement in the patient contribute to this phenomenon. Therefore, avoidance of competitive flow and graft occlusion relies on both adequate surgical strategy and maneuver ${ }^{[33,35]}$. It is perhaps wise to avoid using composite grafts on moderately stenotic coronary arteries particularly moderately stenotic branch in the RCA territory which is the most important predictor of competitive flow and graft occlusion ${ }^{[3,35]}$.

\section{Deep sternal wound infection}

Deep sternal wound infection (DSWI) is a dreadful complication of TAR, especially when BIMA is part of the revascularization strategy. The Arterial Revascularization Trial reported a $1.3 \%$ increase in the incidence of sternal wound reconstruction associated with the BIMA ${ }^{[37]}$. Different techniques of harvesting the IMA may influence these results. DSWI can be reduced to less than $1 \%$ by avoiding BIMA usage in morbidly obese patients (body mass index above 35), insulin-dependent diabetic patients, and those with severe chronic obstructive airways disease, and by appropriate timing of prophylactic antibiotics, including redosing after $4 \mathrm{~h}$, tight blood glucose control intraoperatively and for $48 \mathrm{~h}$, alcohol-based antibacterial preparation, and Vancomycin paste to the sternal edges ${ }^{[27]}$.

Skeletonized technique of IMA harvesting has been shown to conserve considerable collateral flow to the sternum by sparing some of the sternal and intercostal branches that originate from the IMA as a common $\operatorname{trunk}^{[38,39]}$. This technique is claimed to reduce the risk of sternal wound complications by improving wound healing, especially when both left and right IMAs are harvested, due to preservation of sternal blood supply ${ }^{[40]}$.

\section{Other concerns}

Harvesting additional arterial conduits takes an additional 20 to $30 \mathrm{~min}$. However, the avoidance of a proximal anastomosis (in situ RIMA), and the use of sequential anastomoses and "Y" grafts, result in shorter aortic clamp and bypass times, which may benefit myocardial protection and blood element $\operatorname{preservation}^{[27]}$.

Another concern is the potential risk of increased bleeding. A trend towards a higher rate of re-exploration for bleeding in the TAR patients is reported ${ }^{[4]}$, suggesting the need for extra attention during hemostasis when using 3 arterial conduits. 
The single most important and perhaps greatest issue in encouraging adoption of TAR has to be a consideration of data quality. As it has occurred in other areas to which changes to long-standing and previously well-established practices have been recommended, skepticism may well override reason in the absence of "gold standard" prospective RCTs ${ }^{[42]}$. The arena of TAR unfortunately has not enjoyed the benefit of great amounts of such data. As a consequence, even cursory reviews of the available retrospective data readily identify "easy targets" of dissonant data typical of retrospective studies that offer a ready opportunity for disproving the conclusions of these studies ${ }^{[42]}$.

\section{CONTROVERSIES}

\section{Are three arterial grafts better than two?}

Whether the addition of a third arterial conduit (mainly radial artery) to BIMA is associated with better survival than BIMA plus SVGs remains a controversial area, with published literature reporting conflicting results $^{[41,43-51]}$ [Table 2]. Luthra et al ${ }^{[50]}$ in a retrospective, single-center, propensity-matched study compared the impact of a third arterial or venous conduit to the right circulation on early and intermediate survival after CABG in patients with at least two arterial grafts to the left circulation. They failed to demonstrate a significant difference in early or intermediate survival in the propensity-matched groups (venous $v s$. arterial, $99.2 \%$ vs. $99.2 \% ; P=1.000$ at 1 year; $85.2 \%$ vs. $88.8 \% ; P=0.248$ at 5 years and $69.2 \%$ vs. $88.8 \% ; P=$ 0.297 at 7 years). Similarly, Formica and associates ${ }^{[51]}$ comparing the use of radial artery as a third arterial conduit versus SVG failed to show long-term survival benefit of addition of third arterial graft to BIMA. One possible explanation for these contradictory findings is that the survival benefit provided by the use of a third arterial graft is lower when compared with the use of the first or second arterial conduit as most of these single-institutional studies, with small sample sizes, were underpowered to detect moderate differences in survival ${ }^{[52]}$. Interestingly, a meta-analysis of these studies reported that the use of a third arterial graft is not associated with an increase in the operative risk but rather with a $24 \%$ survival benefit at a mean follow-up of 77.9 months ${ }^{[52]}$. Clearly, there is a need for an RCT, preferably multi-institutional, with a large sample size to address this controversy.

\section{Are all configurations of total arterial grafting equal?}

The optimal conduit choice and configuration in achieving TAR remains controversial, with uncertainty regarding the individual prognostic impact of IMAs and supplemental arteries. Shi and associates ${ }^{[53]}$, in a multicentre propensity matched study showed that all configurations of TAR are not equivalent. They compared long-term survival after TAR using single IMA and BIMA supplemented with radial arteries and reported that the use of BIMA as in situ or free conduits is associated with greater survival and seems to offer a prognostic advantage over the use of only a single IMA supplemented by radial arteries. Similar findings were reported by Navia and colleagues ${ }^{[54]}$.

The recently published 10-year final analysis of the Arterial Revascularization Trial (ART), comparing single IMA with BIMA, failed to show significant between-group difference in the rate of death from any cause in the intention-to-treat analysis ${ }^{[5]}$. One plausible explanation offered by the authors for this outcome was that $14 \%$ of the patients who had been randomly assigned to the BIMA group actually underwent single IMA grafting, and $22 \%$ of those who had been randomly assigned to the single IMA group also received a second arterial graft in the form of a radial artery graft. The use of radial artery grafts in ART may be a key confounder, because it is likely to preferentially benefit the single IMA group by the addition of an arterial graft to the second most important coronary artery. When data from patients were analyzed according to the actual receipt of two or more arterial grafts, as compared with a single arterial graft (the as-treated analysis), there appeared to be a meaningfuifference in mortality in favor of multiple arterial grafts $^{[53]}$. It is anticipated that the Randomized Comparison of the Clinical Outcome of Single versus Multiple Arterial Grafts (ROMA) trial ${ }^{[56]}$ will address this controversy. 
Table 2. Key studies comparing impact of three arterial grafts versus two arterial grafts on long-term survival

\begin{tabular}{|c|c|c|c|c|c|c|}
\hline \multirow{2}{*}{ Author } & \multirow{2}{*}{ Year } & \multirow{2}{*}{ Study type } & \multicolumn{2}{|c|}{ PSM Numbers } & \multirow{2}{*}{$\begin{array}{c}\text { Follow-up } \\
\text { Duration (months) }\end{array}$} & \multirow{2}{*}{ Improved survival } \\
\hline & & & 2-Art & 3-Art & & \\
\hline Benedetto et al. ${ }^{[41]}$ & 2016 & PSM & 275 & 275 & 2 -Art $=126 \pm 58.83-$ Art $=126 \pm 54$ & No \\
\hline Di Mauro et al. ${ }^{[43]}$ & 2008 & PSM & 590 & 295 & $\begin{array}{l}2-A r t=88 \\
3-A r t=128\end{array}$ & No^ \\
\hline Glineur $^{[44]}$ & 2013 & PSM & 203 & 93 & $\begin{array}{l}2-\text { Art }=196.8 \pm 74.4 \\
3-\text { Art }=192 \pm 64.8\end{array}$ & Yes \\
\hline Grau et al. ${ }^{[45]}$ & 2015 & PSM & 183 & 183 & $N R(\max 14 \mathrm{y})$ & Yes \\
\hline Locker et al. ${ }^{[46]}$ & 2012 & PSM & $\begin{array}{l}\text { NR } \\
1029^{\star}\end{array}$ & $\begin{array}{l}\text { NR } \\
155^{\star}\end{array}$ & $\begin{array}{l}\text { Mean: } 91.2 \pm 55.2 \\
\text { Median: } 87.6\end{array}$ & Yes \\
\hline Mohammadi et al. ${ }^{[47]}$ & 2016 & PSM & 249 & 249 & $\begin{array}{l}2-A r t=97.8(\mathrm{IQR}, 0.03-22.6) \\
3-\mathrm{Art}=97.2(\mathrm{IQR}, 0.02-17)\end{array}$ & No \\
\hline Nasso et al..$^{[48]}$ & 2012 & PSM & 3584 & 3584 & Mean: 37.2 & No \\
\hline Shi et al. ${ }^{[49]}$ & 2016 & PSM & 262 & 262 & $\begin{array}{l}2-\text { Art }=144 \pm 60 \\
3-\text { Art }=144 \pm 60\end{array}$ & Yes \\
\hline Luthra et al. ${ }^{[50]}$ & 2018 & PSM & 167 & 167 & Max: 7 y & No \\
\hline Formica et al. ${ }^{[51]}$ & 2019 & PSM & 190 & 190 & Max: 18.5 y (IQR, 5.6-13) & No \\
\hline
\end{tabular}

*Non-propensity matched cohort; ^Increased mortality and cardiac death with addition of third arterial conduit (gastroepiploic artery)

Abbreviations: 2-Art: 2 arterial grafts; 3-Art: 3 arterial grafts; IQR: interquartile range; NR: not reported; PSM: propensity score matched

\section{CONCLUSION}

TAR, with its well-recognized benefits of enhanced long-term survival and freedom from re-intervention and cardiac events, is an attractive revascularization option for patients with multi-vessel coronary artery disease. However, the universal adoption remains extremely low due to lack of evidence from RCTs, relatively greater technical complexity and length of the procedure, the perceived increased risk of DSWI and other complications, and the prolonged interval before survival benefits are derived from this strategy. If TAR is to gain popularity then compelling data from RCTs is the single most important strategy to improve uptake of this technique.

\section{DECLARATIONS}

\section{Authors' contributions}

The author contributed solely to the article

\section{Availability of data and materials}

Not applicable.

\section{Financial support and sponsorship}

None.

\section{Conflicts of interest}

All authors declared that there are no conflicts of interest.

\section{Ethical approval and consent to participate}

Not applicable.

\section{Consent for publication}

Not applicable.

\section{Copyright}

(c) The Author(s) 2019. 


\section{REFERENCES}

1. Schwann TA. The surgical treatment of coronary artery occlusive disease: modern treatment strategies for an age old problem. Surg Clin North Am 2017;97:835-65.

2. Raja SG, Sarang Z. Endoscopic vein harvesting: technique, outcomes, concerns \& controversies. J Thorac Dis 2013;5 Suppl 6:S630-7.

3. Motwani JG, Topol EJ. Aortocoronary saphenous vein graft disease: pathogenesis, predisposition, and prevention. Circulation 1998;97:916-31.

4. Loop FD, Lytle BW, Cosgrove DM, Stewart RW, Goormastic M, et al. Inference of the internal mammary artery graft on 10 year survival and other cardiac events. N Engl J Med 1986;314:1-6.

5. Lytle BW, Blackstone EH, Loop FD, Houghtaling PL, Arnold JH, et al. Two internal thoracic artery grafts are better than one. J Thorac Cardiovasc Surg 1999;117:855-72.

6. Pick AW, Orszulak TA, Anderson BJ, Schaff HV. Single versus bilateral internal mammary artery grafts: 10-year outcome analysis. Ann Thorac Surg 1997;64:599-605.

7. Buxton BF, Komeda M, Fuller JA, Gordon I. Bilateral internal thoracic artery grafting may improve outcome of coronary artery surgery. Risk-adjusted survival. Circulation 1998;98:II1-6.

8. Dimitrova KR, Hoffman DM, Geller CN, Dincheva G, Ko W, et al. Arterial grafts protect the native coronary vessels from atherosclerotic disease progression. Ann Thorac Surg 2012;94:475-81.

9. Royse AG, Royse CF, Shah P, Williams A, Kaushik S, et al. Radial artery harvest technique, use and functional outcome. Eur J Cardiothorac Surg 1999;15:186-93.

10. Falk V. Coronary bypass grafting with bilateral internal thoracic arteries. Heart 2013;99:821.

11. Mohr FW, Morice MC, Kappetein AP, Feldman TE, Ståhle E, et al. Coronary artery bypass graft surgery versus percutaneous coronary intervention in patients with three-vessel disease and left main coronary disease: 5-year follow-up of the randomised, clinical SYNTAX trial. Lancet 2013;381:629-38.

12. Taggart DP. How I deploy arterial grafts. Ann Cardiothorac Surg 2018;7:690-7.

13. Raja SG. Surgical strategies for bilateral internal mammary artery grafting. Int J Surg 2015;16:140-5.

14. Lev-Ran O, Pevni D, Matsa M, Paz Y, Kramer A, et al. Arterial myocardial revascularization with in situ crossover right internal thoracic artery to left anterior descending artery. Ann Thorac Surg 2001;72:798-803.

15. Puig LB, França Neto L, Rati M, Ramires JA, da Luz PL, et al. A technique of anastomosis of the right internal mammary artery to the circumflex artery and its branches. Ann Thorac Surg 1984;38:533-4.

16. Paterson HS, Naidoo R, Byth K, Chen C, Denniss AR. Full myocardial revascularization with bilateral internal mammary artery Y grafts. Ann Cardiothorac Surg 2013;2:444-52.

17. Yoshizumi T, Ito T, Maekawa A, Sunada M, Wakai K, et al. Is the mid-term outcome of free right internal thoracic artery with a proximal anastomosis modification inferior to in situ right internal thoracic artery? Gen Thorac Cardiovasc Surg 2012;60:480-8.

18. Damgaard S, Lund JT, Lilleør NB, Perko MJ, Sander K, et al. Comparable three months' outcome of total arterial revascularization versus conventional coronary surgery: copenhagen arterial revascularization randomized patency and outcome trial. J Thorac Cardiovasc Surg 2008;135:1069-75.

19. Tatoulis J, Buxton BF, Fuller JA, Royse AG. Total arterial coronary revascularization: techniques and results in 3,220 patients. Ann Thorac Surg 1999;68:2093-9.

20. Formica F, Ferro O, Greco P, Martino A, Gastaldi D, et al. Long-term follow-up of total arterial myocardial revascularization using exclusively pedicle bilateral internal thoracic artery and right gastroepiploic artery. Eur J Cardiothorac Surg 2004;26:1141-8.

21. Muneretto C, Negri A, Manfredi J, Terrini A, Rodella G, et al. Safety and usefulness of composite grafts for total arterial myocardial revascularization: a prospective randomized evaluation. J Thorac Cardiovasc Surg 2003;125:826-35.

22. Zhao DF, Edelman JJ, Seco M, Bannon PG, Wilson MK, et al. Coronary artery bypass grafting with and without manipulation of the ascending aorta: a network meta-analysis. J Am Coll Cardiol 2017;69:924-36.

23. Muneretto C, Negri A, Bisleri G, Manfredi J, Terrini A, et al. Is total arterial myocardial revascularization with composite grafts a safe and useful procedure in the elderly? Eur J Cardiothorac Surg 2003;23:657-64.

24. Muneretto C, Bisleri G, Negri A, Manfredi J, Metra M, et al. Total arterial myocardial revascularization with composite grafts improves results of coronary surgery in elderly: a prospective randomized comparison with conventional coronary artery bypass surgery. Circulation 2003;108 Suppl 1:II29-33.

25. Muneretto C, Bisleri G, Negri A, Manfredi J, Carone E, et al. Left internal thoracic artery-radial artery composite grafts as the technique of choice for myocardial revascularization in elderly patients: a prospective randomized evaluation. J Thorac Cardiovasc Surg 2004;127:179-84.

26. Tavilla G, Bruggemans EF, Putter H. Twenty-year outcomes of coronary artery bypass grafting utilizing 3 in situ arterial grafts. J Thorac Cardiovasc Surg 2018; doi: 10.1016/j.jtcvs.2018.12.013. [Epub ahead of print]

27. Tatoulis J, Wynne R, Skillington PD, Buxton BF. Total arterial revascularization: achievable and prognostically effective-a multicentre analysis. Ann Thorac Surg 2015;100:1268-75.

28. Yanagawa B, Verma S, Mazine A, Tam DY, Jüni P, et al. Impact of total arterial revascularization on long term survival: A systematic review and meta-analysis of 130,305 patients. Int J Cardiol 2017;233:29-36.

29. Royse AG, Royse CF, Groves KL, Bus B, Yu G. Blood flow in composite arterial grafts and effect of native coronary flow. Ann Thorac Surg 1999;68:1619-22

30. Sakaguchi G, Tadamura E, Ohnaka M, Tambara K, Nishimura K, et al. Composite arterial Y graft has less coronary flow reserve than 
independent grafts. Ann Thorac Surg 2002;74:493-6.

31. Affleck DG, Barner HB, Bailey MS, Perry LA, Maniar H, et al. Flow dynamics of the internal thoracic and radial artery T-graft. Ann Thorac Surg 2004;78:1290-4.

32. Wendler O, Hennen B, Markwirth T, König J, Tscholl D, et al. T grafts with the right internal thoracic artery to left internal thoracic artery versus the left internal thoracic artery and radial artery: flow dynamics in the internal thoracic artery main stem. J Thorac Cardiovasc Surg 1999;118:841-8.

33. Raja SG. Composite arterial grafting. Expert Rev Cardiovasc Ther 2006;4:523-33.

34. Orlov B, Gurevitch J, Kogan A, Rubchevsky V, Zlotnick AY, et al. Multiple arterial revascularization using the tangential K-graft technique. Ann Thorac Surg 2005;80:1948-50.

35. Nakajima H, Kobayashi J, Tagusari O, Bando K, Niwaya K, et al. Competitive flow in arterial composite grafts and effect of graft arrangement in off-pump coronary revascularization. Ann Thorac Surg 2004;78:481-6.

36. Pagni S, Storey J, Ballen J, Montgomery W, Chiang BY, et al. ITA versus SVG: a comparison of instantaneous pressure and flow dynamics during competitive flow. Eur J Cardiothorac Surg 1997;11:1086-92.

37. Taggart DP, Altman DG, Gray AM, Lees B, Nugara F, et al. Randomized trial to compare bilateral vs. single internal mammary coronary artery bypass grafting: 1-year results of the Arterial Revascularisation Trial (ART). Eur Heart J 2010;31:2470-81.

38. De Paulis R, de Notaris S, Scaffa R, Nardella S, Zeitani J, et al. The effect of bilateral internal thoracic artery harvesting on superficial and deep sternal infection: The role of skeletonization. J Thorac Cardiovasc Surg 2005;129:536-43.

39. Kamiya H, Akhyari P, Martens A, Karck M, Haverich A, et al. Sternal microcirculation after skeletonized versus pedicled harvesting of the internal thoracic artery: a randomized study. J Thorac Cardiovasc Surg 2008;135:32-7.

40. Benedetto U, Altman DG, Gerry S, Gray A, Lees B, et al. Pedicled and skeletonized single and bilateral internal thoracic artery grafts and the incidence of sternal wound complications: Insights from the Arterial Revascularization Trial. J Thorac Cardiovasc Surg 2016;152:270-6.

41. Benedetto U, Caputo M, Zakkar M, Bryan A, Angelini GD. Are three arteries better than two? Impact of using the radial artery in addition to bilateral internal thoracic artery grafting on long-term survival. J Thorac Cardiovasc Surg 2016;152:862-9.e2.

42. Rosengart TK. Total arterial revascularization: when will its time come? J Thorac Cardiovasc Surg 2014;148:1244-5.

43. Di Mauro M, Contini M, Iacò AL, Bivona A, Gagliardi M, et al. Bilateral internal thoracic artery on the left side: a propensity scorematched study of impact of the third conduit on the right side. J Thorac Cardiovasc Surg 2009;137:869-74.

44. Glineur D. Importance of the third arterial graft in multiple arterial grafting strategies. Ann Cardiothorac Surg 2013;2:475-80.

45. Grau JB, Kuschner CE, Johnson CK, Ferrari G, Zapolanski A, et al. The effects of using a radial artery in patients already receiving bilateral internal mammary arteries during coronary bypass grafting: 30-day outcomes and 14-year survival in a propensity-matched cohort. Eur J Cardiothorac Surg 2016;49:203-10.

46. Locker C, Schaff HV, Dearani JA, Joyce LD, Park SJ, et al. Multiple arterial grafts improve late survival of patients undergoing coronary artery bypass graft surgery: analysis of 8622 patients with multivessel disease. Circulation 2012;126:1023-30.

47. Mohammadi S, Dagenais F, Voisine P, Dumont E, Charbonneau E, et al. Impact of the radial artery as an additional arterial conduit during in-Ssitu bilateral internal mammary artery grafting: a propensity score-matched study. Ann Thorac Surg 2016;101:913-8.

48. Nasso G, Popoff G, Lamarra M, Romano V, Coppola R,et al. Impact of arterial revascularization in patients undergoing coronary bypass. J Card Surg 2012;27:427-33.

49. Shi WY, Tatoulis J, Newcomb AE, Rosalion A, Fuller JA, et al. Is a third arterial conduit necessary? Comparison of the radial artery and saphenous vein in patients receiving bilateral internal thoracic arteries for triple vessel coronary disease. Eur J Cardiothorac Surg 2016;50:53-60.

50. Luthra S, Leiva-Juárez MM, Matuszewski M, Morgan IS, Billing JS. Does a third arterial conduit to the right coronary circulation improve survival? J Thorac Cardiovasc Surg 2018;155:855-60.e2.

51. Formica F, D’Alessandro S, Singh G, Ciobanu AM, Messina LA, et al. The impact of the radial artery or the saphenous vein in addition to the bilateral internal mammary arteries on late survival: A propensity score analysis. J Thorac Cardiovasc Surg 2019; S00225223(19)30005-4.

52. Gaudino M, Puskas JD, Di Franco A, Ohmes LB, Iannaccone M, et al. Three arterial grafts improve late survival: a meta-analysis of propensity-matched studies. Circulation 2017;135:1036-44.

53. Shi WY, Hayward PA, Tatoulis J, Rosalion A, Newcomb AE, et al. Are all forms of total arterial revascularization equal? A comparison of single versus bilateral internal thoracic artery grafting strategies. J Thorac Cardiovasc Surg 2015;150:1526-33, 1534.e1-3.

54. Navia D, Vrancic M, Piccinini F, Camporrotondo M, Thierer J, et al. Is the second internal thoracic artery better than the radial artery in total arterial off-pump coronary artery bypass grafting? A propensity score-matched follow-up study. J Thorac Cardiovasc Surg 2014; $147: 632-8$.

55. Taggart DP, Benedetto U, Gerry S, Altman DG, Gray AM, et al. Bilateral versus single internal-thoracic-artery grafts at 10 years. N Engl J Med 2019;380:437-46.

56. Gaudino M, Alexander JH, Bakaeen FG, Ballman K, Barili F, et al. Randomized comparison of the clinical outcome of single versus multiple arterial grafts: the ROMA trial-rationale and study protocol. Eur J Cardiothorac Surg 2017;52:1031-40. 